\title{
Impact of abiotic factors on foraging behaviour of major pollinators in sunflower ecosystem
}

\section{AMIT JADHAV AND K. SREEDEVI}

\author{
Article Chronicle : \\ Received : \\ 19.12.2014; \\ Revised : \\ 15.03.2015; \\ Accepted: \\ 05.04 .2015
}

Key Words : Abiotic factors, Correlation, Pollinators, Foraging behaviour
ABSTRACT : Sunflower being a rich oilseed crop in India is widely grown in Karnataka and Andhra Pradesh. It is a highly cross pollinated crop dependent on pollinators for good seed set. Lack of adequate pollinators results in chaffy and partially filled seeds reducing the yield. The pollination in sunflower is carried out mainly by insects both Apis and non Apis sp. whose behaviour and efficiency is largely dependent on weather parameters. The sunflower hybrid was sown and the different pollinators' activity was observed on randomly tagged ten plants for five minutes at hourly interval daily from 06:00h to 19:00h throughout the flowering period during Rabi season of 2009-2010. The meteorological data for the observational period was obtained from Regional Agricultural Research Station located nearby and documented for further correlation studies with pollinators' foraging activity. The studies revealed that the pollinators were foraging maximum during early hours of the day except A. cerana whose activity was maximum in the late hours of the day. The correlation analysis between pollinators' activity and weather parameters revealed that the former was positively correlated with maximum temperature and sunshine hours and negatively correlated with relative humidity, rainfall and wind velocity. Each bee species is guided by specific ecological threshold for normal foraging activity whose maintenance differ intra and interspecifically according to their adaptability.

How to CITE THIS ARTICLE : Jadhav, Amit and Sreedevi, K. (2015). Impact of abiotic factors on foraging behaviour of major pollinators in sunflower ecosystem. Asian J. Environ. Sci., 10(1): 1-6. 